Sofía Correa

Facultad de Derecho

Universidad de Chile

\title{
El corporativismo como expresión política del socialcristianismo
}

\section{LA “CUESTIÓN SOCIAL” EN LA DEFINICIÓN POLÍTICA}

A fines del siglo XIX, la riqueza del salitre trajo consigo una enorme transformación económica y social en Chile, la que produjo entre otras consecuencias, un cambio profundo en las relaciones laborales y también un deterioro en las condiciones de vida de los sectores populares en ciudades, puertos y centros mineros. Las carencias y precariedad de la habitación obrera en los principales centros urbanos -es decir, la miseria de conventillos, cuartos redondos y ranchos-, las deficiencias sanitarias, las epidemias, la altísima mortalidad infantil, las huelgas en el salitre, y en las principales ciudades del centro del país, la mortal represión que las siguió, todo ello fue mostrando a sus contemporáneos una cara hasta entonces desconocida del mundo de los trabajadores (1).

En Chile, quien primero conceptualizó esta nueva realidad y estos nuevos problemas, como "la cuestión social", fue el médico Augusto Orrego Luco en un célebre artículo publicado en la prensa en 1884. Además de médico, Orrego Luco era un destacado político liberal, parlamentario, ministro de Estado, que no estaba solo en esta inquietud por los emergentes problemas sociales. También los parlamentarios liberales Augusto Matte y Manuel Rivas Vicuña manifestaron una activa preocupación por las condiciones de vida de los sectores populares. En el Partido Radical, en la Convención de 1906, Valentín Letelier hizo prevalecer la opción por una postura activa del Estado para enfrentar estos nuevos desafíos. Por otra parte, los universitarios con intereses políticos comenzaban a escribir sus memorias de

(1) Sobre el impacto económico de la riqueza del salitre, véase Carmen Cariola y Osvaldo Sunkel, Un siglo de historia económica de Chile, 1830-1930. Dos ensayos y una bibliografía. (Madrid, Ediciones Cultura Hispánica del Instituto de Cooperación Iberoamericana, 1982; Santiago, Editorial Universitaria, 1990); sobre las condiciones de vida de los sectores populares véase Luis Alberto Romero, Qué hacer con los pobres. Elites y sectores populares en Santiago de Chile 1840-1895 (Buenos Aires, Editorial Sudamericana, 1997); sobre las condiciones laborales en el norte salitrero véase Julio Pinto, Trabajos y rebeldías en la pampa salitrera (Santiago, Editorial Universidad de Santiago, 1998); para una descripción general de la sociedad finisecular véase Sofía Correa et al., Historia del siglo XX chileno. Balance Paradojal (Santiago, Editorial Sudamericana, 2001). 
grado abordando los problemas sociales. Por ejemplo, Arturo Alessandri Palma, siendo estudiante de derecho en la Universidad de Chile, trató en su memoria de titulación los problemas habitacionales, buscando soluciones legislativas a ellos; también abordaron la cuestión social en sus memorias de título el joven conservador Juan Enrique Concha en 1899, y el liberal Manuel Rivas Vicuña en 1903 (2).

En 1891, el entonces diputado liberal, Ramón Barros Luco, presentaba un proyecto de ley de habitaciones obreras, iniciativa que activó siendo Presidente de la República, y que el Congreso aprobó en 1906, constituyéndose en la primera ley social. Al año siguiente se dictaba la primera ley laboral (sobre descanso dominical), iniciativa del parlamentario conservador Alejandro Huneeus, y en 1916 se legislaba sobre accidentes del trabajo, a partir de un proyecto del diputado conservador Alfredo Barros Errázuriz. Todavía más, en 1912 la Cámara de Diputados aprobó la creación de una comisión permanente de legislación social, que fue presidida por Manuel Rivas Vicuña (3).

De modo que la elite dirigente del país no solo no fue indiferente frente a la cuestión social, como se ha sostenido reiteradamente (4), sino que la miró de frente, escribió sobre ella, la analizó, e intentó resolver sus manifestaciones más apremiantes a través de una incipiente legislación social. Asimismo, de lo antedicho se desprende claramente que en todos los partidos políticos de principios del siglo XX había líderes que tenían una fuerte y activa preocupación por los problemas sociales que había traído consigo la modernización finisecular, y que, por tanto, esta inquietud no era exclusiva del ala socialcristiana del Partido Conservador, como se suele argumentar con una cierta intención panegírica (5).

Si la preocupación por los problemas sociales cruzaba los distintos partidos políticos a comienzos del siglo XX, si no es este el rasgo peculiar que distingue a los Conservadores Socialcristianos, entonces tenemos que buscar su especificidad en otra parte. A mi juicio, lo que caracteriza a los socialcristianos es su pretensión de crear un orden político diferente al liberalismo laico imperante y que a su vez fuese una alternativa al socialismo ateo amenazante. Ese orden político no es otro que el corporativismo, un corporativismo antiestatista, basado en la representación política de corporaciones autónomas.

(2) La memoria de Arturo Alessandri Palma, "Habitaciones para obreros" es de 1892. La memoria de derecho de Juan Enrique Concha, "Cuestiones Obreras" es de 1899; la de Manuel Rivas Vicuña, "Instrucción del pueblo" es de 1903. Véase Julio Heise, Historia de Chile. El Período Parlamentario. 1861-1925 (Santiago, Editorial Jurídica, 1974) pp. 359-360. Al respecto también Mario Góngora Ensayo histórico sobre la noción de Estado en Chile en los siglos XIX y XX. (Santiago, Editorial Universitaria, 1986) pp. 95-108.

(3) Véase Julio Heise, Historia de Chile. ... op. cit., pp. 360-361, 377 y siguientes.

(4) Gonzalo Vial ha insistido y popularizado esta idea en su Historia de Chile (1891-1973), vol. 1 tomo 2 (Santiago, Editorial Santillana, 1981).

(5) Lo que sí diferenció a los Conservadores, es decir a los políticos católicos, fue su interés por crear un conjunto de organizaciones de caridad, las que, de una u otra forma, apuntaban a la moralización del pueblo, en la medida en que los Conservadores estaban convencidos que los problemas sociales eran una consecuencia de la falta de valores morales, especialmente referidos a la constitución de la familia, en las clases populares. Véase Sofía Correa Sutil, "La opción política de los católicos en Chile", en Mapocho $\mathrm{N}^{\circ}$ 46, segundo semestre 1999, pp. 191-201. 


\section{UN ORDEN POLÍTICO CATÓLICO}

Muy tempranamente podemos encontrar entre los Conservadores una concepción del orden político que no se condice con el pensamiento liberal, a pesar de su adhesión a la organización republicana. Por ejemplo, en 1868 Abdón Cifuentes afirmaba que la sociedad no era una suma de individuos portadores de derechos, como aseguraba el liberalismo, sino que una entidad natural a la vez que histórica, conformada por un conjunto de estamentos que debían gozar de los mismos derechos y libertades que los individuos, y debían estar representados en el poder estatal (6). Me parece que apenas iniciando la segunda mitad del siglo XIX aún no estamos en presencia de un lenguaje corporativista, es decir, moderno, sino que más bien el discurso de Abdón Cifuentes en 1868 sería premoderno, aunque capaz, por cierto, de transformarse eventualmente en un discurso corporativista. Su noción de libertad no es la que manejaban los liberales. Como diputado, en 1873, Cifuentes defendía a las "asociaciones" como "siempre benéficas para los pueblos y necesarias, indispensables en las democracias, donde quiera que existan las libertades populares" (7). Por tales entendía aquellas que habrían prevalecido en la España preborbónica, "la primera maestra de las libertades populares", agregando que en "las comunidades y en las hermandades de Galicia, de Castilla y Aragón, fue donde se cultivó mejor el espíritu de libertad y de independencia personal", de modo que cuando "el despotismo monárquico acabó con las hermandades y asociaciones, acabaron también las libertades públicas y comenzó para España esa larga decadencia" (8). Sería entonces en las asociaciones, o lo que viene a ser lo mismo, en las "comunidades" y "hermandades", donde se materializaría la libertad, que en Cifuentes adquiere el adjetivo de popular. Sobre la base de las asociaciones así concebidas, Abdón Cifuentes propuso crear una "república democrática y cristiana" (9), que sería diferente, suponemos, de la república liberal.

Así, estamos ante un lenguaje político católico en el que el concepto de libertad y las formas ideales de organización política se diferencian sustantivamente de lo que propone el liberalismo. En cambio, estamos llamativamente cerca de la interpretación histórica que levantaría décadas más tarde el discurso corporativista socialcristiano, difundido con elocuencia por Jaime Eyzaguirre en la primera mitad del siglo XX, el que, como es bien sabido, tenía como referente paradigmático a la España preborbónica.

El pensamiento protocorporativista de Abdón Cifuentes tuvo que confrontar al interior del Partido Conservador a un grupo pequeño pero potente intelectualmente de católicos liberales, que aspiraban a definir al partido fundamentalmente por su rechazo al autoritarismo presidencial y a la intervención electoral del Ejecutivo que

(6) Véase Alfredo Riquelme Segovia, “Abdón Cifuentes frente a la laicización de la sociedad. Las bases ideológicas”, en Ricardo Krebs, et al., Catolicismo y Laicismo. Las bases doctrinarias del conflicto entre la Iglesia y el Estado en Chile. 1875-1885. Seis estudios. (Santiago, Ediciones Nueva Universidad, 1981), p. 129. Las cursivas son mías.

(7) Citado por Alfredo Riquelme Segovia, op. cit., pp.132-133. Las cursivas son mías.

(8) Citado por Alfredo Riquelme Segovia, op. cit., p.137. Las cursivas son mías.

(9) Véase Alfredo Riquelme Segovia, op. cit., p.122. 
lo hacía posible, más que por su carácter religioso. Su figura más visible fue Zorobabel Rodríguez (10), discípulo de Courcelle Seneuil, profesor de la cátedra de economía política en la Facultad de Derecho, diputado, columnista y editor del diario El Independiente del Partido Conservador. A diferencia de Cifuentes, para Zorobabel Rodríguez, libertad, progreso y razón se vinculaban entre sí indisolublemente, tanto que la historia de la humanidad la veía como la historia del progreso de la libertad, entendida esta como el imperio de las leyes naturales (incluidas las leyes que regirían el comportamiento de las sociedades), que él las entendía como las leyes de la voluntad de Dios. A la sociedad la concebía como una agregación de individuos, de modo que la suma de intereses individuales en libre competencia daba origen al interés general. El Estado debía tener una jurisdicción limitada en la medida en que los individuos le habrían delegado su soberanía solo para que este les asegurara la preservación del orden, la seguridad y la libertad. Doctrinariamente, no cabía duda que Zorobabel Rodríguez era un liberal, tanto que todo su esfuerzo intelectual expresado en sus columnas de opinión en la prensa, se concentraba en demostrar la armonía que él reconocía entre liberalismo y catolicismo.

Los Conservadores liberales, encabezados por Zorobabel Rodríguez combatieron las leyes laicas de la década de 1880, apelando a la defensa de la libertad y autonomía individual frente a la imposición estatal de su proyecto de laicización, llegando a proponer incluso la separación de la Iglesia y el Estado para asegurar la autonomía eclesiástica. Así es que, cuando se aprobaron las leyes laicas en 18831884, el catolicismo liberal quedó completamente derrotado como expresión política legítima de los católicos chilenos. La jerarquía eclesiástica le dio todo su apoyo a la vertiente ultramontana del Partido Conservador, la que tenía como una de sus figuras más destacadas a Abdón Cifuentes. Más aún, en 1886 una pastoral colectiva del episcopado chileno condenaba al liberalismo y al catolicismo liberal. En 1884, Zorobabel Rodríguez debió dejar la dirección de El Independiente y su columna diaria en él, y se debió limitar al comentario de temas únicamente económicos en el periódico conservador La Unión de Valparaíso, llegando al punto incluso que a partir de 1891 se vio obligado a dejar de escribir enteramente en la prensa. No es raro entonces que el Tratado de Economía Política de Zorobabel Rodríguez fuese texto de cátedra en la Universidad de Chile, mientras que en la recién fundada Universidad Católica fuese considerado sospechoso de herejía (11).

Aún más, con el propósito de revertir el proceso de laicización en curso, en 1883 monseñor Joaquín Larraín Gandarillas le propuso a Abdón Cifuentes que organizara a los católicos en defensa de sus intereses religiosos. A raíz de ello, se crearon los Círculos Católicos y la Unión Católica, organización político-religiosa controlada por la jerarquía eclesiástica. Se crearon centros católicos "de cohesión y propaganda", círculos de obreros, círculos de jóvenes, un colegio católico que fuera equivalente al

(10) Sobre Zorobabel Rodríguez y el catolicismo liberal, véase Sofía Correa Sutil, "El Partido Conservador ante las leyes laicas. 1881-1884" en Ricardo Krebs, et al., op. cit., pp. 75-118; Sofía Correa, "Zorobabel Rodríguez, católico liberal", en Estudios Públicos N 66, otoño 1997, pp. 387-426; Sofía Correa, “'De Nuestra Inferioridad Económica'. Reflexiones sobre los límites del desarrollo capitalista chileno", en Estudios Públicos N 73, 1999, pp. 401-430.

(11) Ello debido a su aceptación de la ley de Malthus y por ser partidario de la separación de la Iglesia y el Estado. 
Instituto Nacional (el Instituto de Humanidades) y una universidad católica en la que pudieran refugiarse los jóvenes provenientes de colegios de congregaciones religiosas, que de lo contrario tenían que estudiar en la descreída Universidad de Chile. Es decir, se formó toda una red de organizaciones militantemente católicas paralelas a aquellas donde prevalecían los sectores anticlericales. Abdón Cifuentes, ha dicho uno de sus estudiosos, desplegó una intensa actividad como "organizador de instituciones de defensa extraparlamentaria de las posiciones de la Iglesia Católica, para oponerse al proceso de laicización de la sociedad y el Estado" (12). Por otra parte, con la derrota y desplazamiento de los católicos liberales, el Partido Conservador se reorganizó definitivamente como un partido clerical ultramontano.

He ahí, pues, el vínculo entre este proceso decimonónico y las opciones políticas del socialcristianismo de las décadas de 1920 y 1930, a saber: la apuesta por las asociaciones como espacio para la "libertad popular"; la desconfianza en los partidos políticos como canales de representación ciudadana, y en el Congreso Nacional como el espacio por excelencia para la acción política; así como el propósito primordial y expreso de retornar a un Estado verdaderamente confesional.

En 1891, el corporativismo como expresión política del orden socialcristiano recibe un nuevo impulso con la Encíclica Rerum Novarum. Desde el punto de vista del pensamiento político esta encíclica ha de ser entendida como una propuesta corporativista, en la medida en que plantea actualizar los viejos gremios medievales e instala la visión de la familia como sociedad natural, anterior a la constitución de la "sociedad civil". Al respecto afirma Ludovico Incisa que es en Rerum Novarum donde "el modelo corporativo asume una configuración doctrinaria más precisa y menos nostálgica" (13).

\section{EL CORPORATIVISMO SOCIALCRISTIANO 1920-1930}

En la década de 1920, la crisis de la política liberal y de los partidos históricos como canales de representación ciudadana, dio un renovado impulso a los socialcristianos, que ahora buscaron distanciarse del Partido Conservador, respecto del cual tenían una mirada crítica y escéptica. Por eso, el socialcristianismo se presentó como "catolicismo social". Mario Góngora (14) menciona como figuras destacadas de esta nueva expresión del socialcristianismo, a los sacerdotes Alejandro Huneeus, Guillermo Viviani y Fernando Vives, quien creara la Liga Social, asociación católica cuyo propósito era realizar acción social al margen de los partidos. En ella participaron activamente Jaime Eyzaguirre y Julio Philippi, dos destacados intelectuales socialcristianos que tuvieron una notoria participación pública años más tarde, el uno como historiador, el otro como político (15).

(12) Véase Alfredo Riquelme Segovia, op. cit., p. 121. Las cursivas son mías.

(13) Ludovico Incisa, "Corporativismo", en Norberto Bobbio, Nicola Matteucci, Gianfranco Pasquino, Diccionario de Política (Madrid, Siglo XXI Editores, 10a edición en español, 1997) p. 373.

(14) Mario Góngora, Ensayo histórico op . cit., pp. 228-235.

(15) Véase Carlos Ruiz, "Corporativismo e hispanismo en la obra de Jaime Eyzaguirre" en Renato Cristi y Carlos Ruiz, El Pensamiento Conservador en Chile (Santiago, Editorial Universitaria 1992) pp. 67-102. Julio Philippi fue ministro de Estado bajo el gobierno de Jorge Alessandri. 
Este distanciamiento respecto al partido católico, que todavía contaba con el decidido respaldo de la jerarquía eclesiástica, continuó en la década siguiente. En efecto, a principios de los años 30 se habían organizado los Círculos de Estudios y la Acción Católica, en forma paralela a la organización política partidista (16). Pertenecieron a estos círculos toda una generación de jóvenes católicos, donde destacaron Jaime Eyzaguirre, Osvaldo Lira (algo mayor), Clotario Blest, Jaime Larraín García Moreno, Armando Roa, Roque Esteban Scarpa, Eduardo Frei, Manuel Garretón, Bernardo Leighton, Ignacio Palma, Jorge Prat, Jaime Castillo, entre otros (17). Menciono sus nombres pues todos ellos tuvieron notoria actuación política e intelectual en las décadas siguientes, aunque diversificaron sus posiciones políticas y doctrinarias en campos muchas veces opuestos (18). Por eso, el historiador Mario Góngora, quien también fue parte de esta corriente afirmó: "Los focos de la renovación juvenil católica fueron la Acción Católica Universitaria, dirigida por Oscar Larson y la revista Estudios, dirigida por Jaime Eyzaguirre" (19). Sabemos que en la revista Estudios escribían asiduamente también Fernando Vives, Osvaldo Lira, Armando Roa, Julio Philippi, formando entre sí un grupo doctrinariamente homogéneo (20).

Los socialcristianos de la década de 1930, fuertemente influidos por la Encíclica Quadragessimo Anno, de 1931, insistieron en la necesidad de establecer una organización política corporativista en reemplazo del orden político liberal (21). El corporativismo católico tiene una concepción orgánica de la sociedad, según la cual la sociabilidad humana se expresa a través de organizaciones de carácter natural, es decir constitutivas de la naturaleza humana. Específicamente, estas organizaciones son la familia, el municipio, la región y la corporación; a su vez esta última contiene al gremio y al sindicato (22). Se trata, por cierto, de una concepción del sindicato muy distinta que la que planteaban las vertientes socialistas, pues en el corporativismo católico la finalidad del sindicato no era la lucha política sino que, por el contrario, el sindicato buscaba conciliar los intereses contrapuestos y velar por el perfeccionamiento moral y cultural de sus miembros (23). Para el corporativismo

(16) Véase Sofía Correa Sutil, "La opción política ..." op. cit.

(17) Véase Mario Góngora, Ensayo Histórico ... op. cit., p. 235 nota 135.

(18) Por ejemplo, Clotario Blest fue dirigente sindical, creó la CUT en 1952, y en los años setenta fue cercano al MIR; Jorge Prat fue dirigente nacionalista, candidato a la Presidencia de la República por algunos meses en 1964; Jaime Larraín García Moreno fue el primer presidente que tuvo la Confederación de la Producción y del Comercio y fundó el Partido Agrario (corporativista) luego Partido Agrario Laborista, al cual renunció para crear otro partido nacionalista; Manuel Garretón fue uno de los fundadores de la Falange Nacional.

(19) Mario Góngora, Ensayo Histórico ... op. cit., p. 235 nota 135.

(20) Véase Carlos Ruiz, "Corporativismo e hispanismo ...” op. cit., Osvaldo Lira, Armando Roa, Jaime Eyzaguirre y Julio Philippi fueron intelectuales reconocidos en el campo del pensamiento de derecha en los años posteriores.

(21) Véase Fernando Vives Solar, s.j., "Bases para una constitución cristiana del Estado" (1932) reproducido en Escritos del padre Fernando Vives Solar (Fuentes para la historia de la República, vol. v, Dirección de Bibliotecas, Archivos y Museos, 1993) pp. 229-246.

(22) Véase Sofía Correa Sutil, "El pensamiento en Chile en el siglo XX bajo la sombra de Portales", en Oscar Terán, coordinador, Ideas en el siglo. Intelectuales y cultura en el siglo XX latinoamericano (Buenos Aires, Siglo XXI editores, 2004) pp. 251 y siguientes.

(23) Véase Carmen Fariña, "Notas sobre el pensamiento corporativo de la Juventud Conservadora a través del periódico Lircay (1934-1940)" Revista de Ciencia Política, 1987. pp. 119-142; véase también Ludovico Incisa, "Corporativismo", op. cit. 
socialcristiano, tanto el gremio como el sindicato, es decir, las corporaciones, debían tener un carácter compulsivo, debían ser obligatorias para todos los que "actúan en una misma profesión, en calidad de patronos, de empleados, de obreros o de técnicos" y las decisiones "que la autoridad del cuerpo adopte" debían ser acatadas por todos ellos (24). Al armonizar los intereses del capital y del trabajo, se podría superar la lucha de clases.

Estas "organizaciones naturales", es decir, la familia, el municipio, la región y la corporación, debían formar el "Estado armónico" (25), en una "democracia orgánica" (26). El reconocimiento de las regiones debía hacerse sin poner en peligro la unidad nacional. En palabras de Eduardo Frei, a semejanza del cuerpo humano que es una unidad, "en un país, la vitalidad de las regiones no debe producirse en desmedro de la unidad sino en beneficio del todo, lo que se consigue en un Estado que, desprendiéndose de estas funciones particulares para las cuales no tiene competencia, puede imprimir una firme y alta orientación a toda la vida nacional" (27). El Estado debía concentrar poder suficiente para hacer prevalecer el "interés general" por sobre el interés particular, pues "las iniciativas privadas pueden olvidar el interés general o aun oponerse a él. Ponerlas de acuerdo, hacerlas concurrir al bien público y, por consiguiente controlarlas y vigilarlas, orientarlas, es evidentemente un derecho de la autoridad pública", aseguraba Fernando Vives (28). La organización del Estado debía contemplar la representación de las corporaciones y limitar el sufragio universal, por lo que propusieron la composición corporativa del Senado, acogiendo en él a los gremios empresariales y a los colegios profesionales (29).

En suma, en vez de concebir la sociedad política a partir de un contrato entre individuos como lo hace el pensamiento liberal, los corporativistas socialcristianos, apoyados en la filosofía escolástica, concibieron la sociedad como un organismo, el cual estaría estructurado jerárquicamente en base a las sociedades intermedias. En esta perspectiva, la noción de "bien común" tomaba el lugar que el liberalismo le había asignado a la soberanía popular (30).

Si bien marcaron diferencias con el fascismo europeo, los socialcristianos chilenos se mostraron complacientes con los ensayos corporativistas de Dolfuss en Austria y de Oliveira Salazar en Portugal (31). Pensaron que era el orden corporativo socialcristiano el que permitiría asegurar una institucionalidad política católica; por lo tanto, plantearon que había que comenzar por revertir la laicización del

(24) Jaime Eyzaguirre, "Elementos de la ciencia económica” (1937), citado por Carlos Ruiz, "Corporativismo e hispanismo ...", op. cit., p. 82.

(25) Fernando Vives Solar, s.j., "Individualismo", La Unión, 8 de enero de 1934, reproducido en El humanismo de Fernando Vives (Santiago, Instituto Chileno de Estudios Humanísticos, 1976), p. 129.

(26) Eduardo Frei, Chile Desconocido (Santiago, Ediciones Ercilla, 1937) p. 165.

(27) Ibidem, p. 136.

(28) Fernando Vives Solar, s.j., "Bases para una constitución ...” op. cit., p. 243.

(29) Véase Sofía Correa Sutil, "El pensamiento en Chile ...” op. cit., p. 257.

(30) Véase Sofía Correa Sutil, "El pensamiento en Chile ...op. cit., pp. 258-259.

(31) Véase Gonzalo Vial, "El pensamiento social de Jaime Eyzaguirre" en Dimensión Histórica de Chile $\mathrm{N}^{\circ}$ 3, 1986, y Gonzalo Larios Mengotti, "Jaime Eyzaguirre, visión política y corporativismo", en Walter Hanisch Espíndola, s.j., et al., Jaime Eyzaguirre, historia y pensamiento (Santiago, Editorial Universitaria, 1995). 
Estado y de la sociedad para asegurar que los principios religiosos organizaran la vida social, económica y política. De hecho, Fernando Vives definía al "catolicismo social" como "una reacción decisiva contra el régimen de laicización de la sociedad" (32).

El corporativismo socialcristiano no tuvo una buena acogida en el Partido Conservador, ni tampoco en la jerarquía eclesiástica. Después de la guerra civil de 1891, el Partido Conservador, con una significativa representación parlamentaria, se movía cómodamente en el espacio político generado a partir del sufragio universal masculino. La jerarquía eclesiástica, por su parte, había logrado construir una armónica convivencia en el sistema político liberal, y su capacidad de veto político no era despreciable. Así, los dirigentes Conservadores rechazaron en los socialcristianos tanto que postularan un orden económico no capitalista, como que propusieran que la representación corporativa reemplazara al sufragio como fuente de representación política. Me parece que esta es la clave con la cual debe entenderse el distanciamiento de los Conservadores respecto al socialcristianismo de las décadas de 1920 y 1930, a saber, como la disputa entre quienes defendían la organización republicana liberal por una parte, es decir los Conservadores, y quienes querían reemplazarla por el corporativismo católico, es decir los Socialcristianos.

\section{DOS OPCIONES EN JUEGO}

La relación con la política fue lo que vino a quebrar la unidad del grupo de jóvenes socialcristianos que, hasta comienzos de la década de 1930, se había tan solo congregado en torno a círculos de estudios y revistas culturales. Poco después de la caída de la dictadura ibañista, una fracción decidió, impulsada por la jerarquía eclesiástica, integrarse al Partido Conservador para participar activamente en política. Formaron la Juventud Conservadora o Falange Nacional, nombre tomado de su homónima española, que era un movimiento católico corporativista, si es que no fascista (33). Permanecieron en el Partido Conservador entre 1933 y 1939, período en el cual este formaba parte de la alianza que respaldaba al gobierno de Arturo Alessandri, y dejaron el partido cuando este perdió la elección presidencial y quedó solamente con representación parlamentaria. En esos años, integrando las listas del viejo partido, los falangistas lograron hacer elegir como diputados a sus líderes más connotados y asumieron carteras ministeriales en calidad de miembros del Partido Conservador.

Mientras un sector de los jóvenes socialcristianos comenzaba a hacer un rápido aprendizaje político, otro grupo, en cambio, mantuvo su rechazo a los partidos y a la organización liberal, acentuando tanto el ideario corporativista socialcristiano como

(32) Fernando Vives Solar, s.j., "Catolicismo y catolicismo social”, La Unión, 22 de febrero de 1934, reproducido en El humanismo de ... op. cit., p. 93.

(33) Aunque Mario Góngora en Ensayo histórico, op. cit, p. 249, ha hecho notar que en la Falange Nacional chilena hubo una mayor influencia de Acción Popular de Gil Robles, cercana a la Acción Católica, que de la Falange de Primo de Rivera. Ambos, eso sí, eran movimientos corporativistas. 
su postura antioligárquica. Es posible que sea la dureza de su discurso antioligárquico y antiliberal, muchísimo más radical que el de los jóvenes falangistas, el que haya llevado a muchos a considerarlos dentro de los sectores "progresistas" del período. Destacaron como parte de este sector socialcristiano el sacerdote Fernando Vives y Jaime Eyzaguirre. En la década de 1930, estos corporativistas socialcristianos, siguiendo las recomendaciones de las encíclicas sociales, apostaron a la construcción de una "democracia cristiana", por oposición a la democracia liberal, la que habría de darse fundamentalmente en el plano social, como un sentimiento y un deber y no como régimen, planteaba Fernando Vives, quien, por eso mismo, prefería hablar de "demofilia" antes que de democracia, concepto que consideraba demasiado liberal para que pudiera ser aceptable (34).

Pero no solo estos socialcristianos antipartidos continuaron adhiriendo a las posturas corporativistas. También los socialcristianos políticos, los falangistas, las mantuvieron por algunos años más. Tanto así que en 1937, Eduardo Frei, dirigente a la sazón de la Juventud Conservadora, proponía "la muerte del viejo Estado liberal e inorgánico y el nacimiento de una nueva sociedad orgánica y jerárquica", conducida por un gobierno fuerte, que impulsara "una política verdaderamente nacional y orgánica" (35). En su periódico Lircay, los falangistas plantearon que la realización del "bien común" requería "de un orden que jerárquicamente subordine los elementos sociales, sin destruirlos, al bien público general que el Estado persigue e impone" (36). Sin embargo, su misma decisión de participar activamente en la política partidista, primero integrando la Juventud del Partido Conservador y luego escindiéndose de este para crear un partido nuevo, los fue alejando de las concepciones corporativistas sobre la organización social y política. Además, muy pronto, los acontecimientos europeos les llevarían a abandonar este ideario.

En efecto, en la medida en que el corporativismo se había materializado históricamente en el fascismo, la derrota de las potencias del Eje en la Segunda Guerra Mundial llevó al descrédito total de las opciones corporativistas. El mismo Vaticano las abandonó, como quedó de manifiesto en la Alocución de Navidad de Pío XII en 1944, para legitimar en vez a la democracia liberal y poder convertirse así en un aliado de los Estados Unidos para enfrentar al comunismo. Los católicos que habían combatido a los regímenes fascistas en Italia, Alemania y Francia organizaron un nuevo referente político, los partidos demócrata cristianos, los cuales muy pronto, con el apoyo del Vaticano y de los Estados Unidos, comenzaron a gobernar sus respectivos países, introduciendo reformas económicas y sociales. Solamente la España de Franco y el Portugal de Oliveira Salazar insistían todavía en la implementación de un orden corporativista de raíz católica, pero ambos países quedaron aislados en el concierto internacional, hasta que, en el caso de España, se abandonó el corporativismo para adoptar una política económica capitalista de libre mercado, una década más tarde.

Los acontecimientos de la política europea tuvieron un fuerte impacto en los católicos chilenos. Por de pronto, provocaron en 1949 la división del Partido Con-

(34) Fernando Vives Solar, s.j., "Democracia", La Unión, 5 de octubre de 1934. Reproducido en El humanismo ... op. cit., pp. 83-84. 
servador. En 1946 se había formado en él una corriente socialcristiana que aspiraba a seguir los pasos de los partidos demócrata cristianos europeos; pretendía "cristianizar" la vida económica y se planteaba como alternativa política frente al liberalismo y al socialismo. Las posturas de los Conservadores Socialcristianos fueron más bien populistas que corporativistas, y terminaron integrando la Democracia Cristiana cuando este partido se creó en 1957 (37).

Como efecto de los acontecimientos de la política europea de postguerra, los corporativistas socialcristianos integristas, es decir aquellos que como Fernando Vives y Jaime Eyzaguirre se habían negado a integrarse al proceso político liberal, se refugiaron intelectualmente en el hispanismo, el de la España católica y barroca del siglo de oro, para desde allí mantener el ideario corporativista, que ahora denominaron "gremialista" (38). No fue tanto la España franquista la que selló el vínculo entre hispanismo y corporativismo en Jaime Eyzaguirre, sino algo menos contingente, su visión histórica, según la cual "el sentimiento de independencia y de libertad" presente en los fueros medievales se prolongaba en el cabildo americano (39). Planteaba Jaime Eyzaguirre que Chile tenía que recuperar su alma, volviendo a la tradición, lo que implicaba revitalizar el cabildo, es decir, el municipio, como cuerpo intermedio de la sociedad. Centrando la mirada en la España del siglo de oro, distinguía entre soberanía social y soberanía política (40). Para ejemplificarlas, señaló que la soberanía política era la que le correspondía al rey, mientras que la soberanía social era la que le pertenecía al cabildo, el cual en América, en ocasiones, también habría asumido la soberanía política a nombre del rey. Sobre esta distinción se habría asentado en América durante el período español, el orden corporativo, cuando el cabildo, encarnando los ideales del bien común, ejercía atribuciones de regulación económica, obligando a los "intereses particulares" a doblegarse ante este (41).

Los falangistas, en cambio, inspirados en las obras de Maritain y guiados por las nuevas directrices emanadas del Vaticano, abandonaron el ideario corporativista y abrazaron la democracia liberal y la economía capitalista, proponiendo reformas para modernizar las estructuras económicas y sociales semejantes a las que se estaban implementando en Europa para crear un Estado de Bienestar. Cuando los falangistas fundaron la Democracia Cristiana, en 1957, habían abandonado todo vestigio del corporativismo socialcristiano que habían defendido en décadas anteriores.

Ello no obstante, como hiciera notar Mario Góngora, en importantes sectores del Partido Demócrata Cristiano se habría mantenido vivo el corporativismo social-

(35) Eduardo Frei, Chile Desconocido, op. cit., pp. 139, 145.

(36) Citado por Carmen Fariña, "Notas sobre ..." op. cit., p. 40.

(37) Véase Sofía Correa Sutil, Con las riendas del poder. La derecha chilena en el siglo XX (Santiago, Editorial Sudamericana, 2005) capítulo 3.

(38) Véase Carlos Ruiz, "Corporativismo e hispanismo ...” op. cit., y Sofía Correa Sutil, "El pensamiento en Chile ..." op. cit.

(39) Jaime Eyzaguirre, Hispanoamérica del Dolor (Santiago, Editorial Universitaria, 1969) p. 21.

(40) Sofía Correa Sutil, "El pensamiento en Chile ...", op. cit., p . 272.

(41) Jaime Eyzaguirre, Hispanoamerica del Dolor, ... op. cit., pp. 57. Las nociones de soberanía política y soberanía social fueron reproducidas posteriormente por Jaime Guzmán. Sobre el pensamiento de Jaime Eyzaguirre, véase Carlos Ruiz. "Corporativismo e hispanismo ..." op. cit., Sobre el pensamiento de Jaime Guzmán, véase Renato Cristi, El pensamiento político de Jaime Guzmán. Autoridad y libertad. (Santiago, Lom Ediciones, 2000). 
cristiano, bajo la denominación de "comunitarismo", en cuanto anhelo de crear una organización política que constituyera una alternativa diferente al liberalismo y al socialismo (42). Incluso, tan tardíamente como en 1959, un articulista afirmaba en Política y Espíritu, la revista doctrinaria de la Democracia Cristiana, que "la noción de bien común está ligada a la noción de sociedad orgánicamente constituida”, para asegurar en seguida que el bien común "tiende a desaparecer en donde imperen filosofías individualistas o un régimen anárquico de partidos" (43). Incluso en la década de 1960, en círculos intelectuales de la Democracia Cristiana se seguía escribiendo sobre la sociedad orgánica, el Estado orgánico, la democracia orgánica, las corporaciones, e incluso sobre el "corporativismo social" (44). Hasta podría afirmarse que un conjunto de políticas implementadas bajo el gobierno democratacristiano tienen esta impronta; por de pronto, las políticas de regionalización, y la promoción popular con sus organizaciones de base funcionales (como los centros de madres) y territoriales (como las juntas de vecinos), que reflejarían la vieja preferencia del corporativismo socialcristiano por los organismos intermedios como la familia, el municipio, la región, además de la corporación (45).

\section{EL SOCIALCRISTIANISMO EN LA CONSTITUCIÓN DEL 80}

No es extraño, por tanto, que pocos años más tarde nos encontremos con constitucionalistas socialcristianos de la vertiente falangista teniendo una activa participación en la redacción de la Constitución de 1980. En efecto, el presidente del Partido Demócrata Cristiano, Patricio Aylwin, habría ejercido presiones ante el Ministro de Justicia de la dictadura, para que se integraran juristas de este partido a la recién creada Comisión Constituyente. En consecuencia fueron invitados a participar en ella Alejandro Silva Bascuñán y Enrique Evans, quienes formaron parte de dicha Comisión Constituyente entre septiembre de 1973 y marzo de 1977 (46). Allí participaron junto a católicos corporativistas, como Jaime Guzmán, de 27 años a la sazón, formado intelectualmente por el sacerdote Osvaldo Lira y por Jaime Eyzaguirre, a quienes habíamos visto teniendo en los años 20 una activa participación en las organizaciones socialcristianas tales como los Círculos de Estudios y la Revista Estudios.

Jaime Guzmán fue quien redactó los primeros documentos del régimen militar, por de pronto, la Declaración de Principios del Gobierno de Chile, que firmaron los cuatro comandantes en jefe que dieron el golpe de Estado y que publicitaron algunos meses después (47). Si bien este documento sintetizó coherentemente las distintas

(42) Mario Góngora, Ensayo histórico ... op. cit., p. 250.

(43) Carmen Fariña, "El pensamiento corporativo en las revistas Estanquero (1946-1955) y Política y Espíritu (1945-1975)" en Revista de Ciencia Política 1990, p. 133.

(44) Ibidem.

(45) Carmen Fariña ha hecho notar que Eduardo Frei se opuso a cualquier intento de rescatar el corporativismo, en "El pensamiento ..." op . cit.

(46) Robert Barros, La Junta Militar, Pinochet y la Constitución de 1980 (Santiago, Editorial Sudamericana, 2005) p. 120.

(47) Véase Renato Cristi, El pensamiento político ... op. cit. 
corrientes que apoyaban a la Junta Militar, nacionalistas y neoliberales por ejemplo, prevaleció en él como matriz el socialcristianismo corporativista. Curiosamente, la Declaración comienza con un planteamiento filosófico sobre la naturaleza humana y la sociedad, para tratar enseguida una teoría del Estado. Se tomó distancia del liberalismo y del marxismo, y desde allí se definió un concepto central, el de bien común. De este se derivó el principio de subsidiariedad que permitía asegurar la autonomía de los cuerpos intermedios, autonomía que se identificaba con la vigencia de la libertad. A continuación la Declaración afirmaba que sobre estos principios se crearía una nueva institucionalidad, que tendría como fundamentos la "descentralización funcional" y la "descentralización territorial". Esta última se basaría en la región como la unidad fundamental, en tanto la "descentralización funcional" tendría como fundamento la distinción entre "poder político y poder social", adscribiendo el poder social al municipio, recogiendo así las ideas del corporativismo socialcristiano que habíamos visto desarrolladas por Jaime Eyzaguirre (48). Al poder político le entregaba "la función de gobernar al país", mientras que el poder social era definido como "la facultad de los cuerpos intermedios de la sociedad para desarrollarse con legítima autonomía hacia la obtención de sus fines específicos". En otras palabras, el "poder social" estaba "llamado a convertirse en el cauce orgánico más importante de expresión ciudadana”, y por tanto debía ser despolitizado, así como todas las asociaciones intermedias porque de otra manera no podían ser cauce del poder social (49).

Con respecto a la Constitución de 1980, promulgada durante la dictadura militar, la presencia de los socialcristianos en la Comisión Constituyente, le imprimió a esta un carácter corporativista, reflejado sobre todo en las "bases de la institucionalidad", capítulo inicial de la Constitución donde se introducen declaraciones filosóficas sobre la organización de la sociedad. Por ejemplo, sabemos por el mismo Jaime Guzmán que el concepto de "bien común" que consagra la Constitución en las "bases de la institucionalidad", fue discutido por la Comisión Constituyente en junio de 1974 para dejar establecido que este tenía un significado unívoco, a saber, en palabras de Guzmán, "en el sentido que no hay más que uno aceptable” pues el bien común no es "la simple suma de bienes individuales" ni tampoco "un bien de la colectividad" (50). Por cierto, también otros artículos constitucionales que definen las bases de la institucionalidad, tienen un definido carácter corporativista. Por ejemplo, en el artículo primero se declara que "la familia es el núcleo fundamental de la sociedad. El Estado reconoce y ampara a los grupos intermedios a través de los cuales se organiza y estructura la sociedad y les garantiza la adecuada autonomía para cumplir sus fines específicos. ... su finalidad es promover el bien común ...". Incluso la regionalización quedó consagrada en las bases de la institucionalidad, asegurándose allí también el Estado unitario, tal como lo planteaban los socialcris-

(48) Sobre la Declaración de Principios de la Junta de Gobierno, véase Sofía Correa Sutil, "El pensamiento ...." op. cit., pp. 290-296.

(49) La "Declaración de Principios del Gobierno de Chile" está reproducida en Sofía Correa et al., Documentos del siglo XX chileno (Santiago, Editorial Sudamericana, 2003), pp. 428-444.

(50) Jaime Guzmán, "El concepto de "bien común” y la Constitución de 1980: Actas de la Comisión Constituyente (1974)", reproducido en Estudios Públicos N 42, 1991. 
tianos de los años 30. También la despolitización de las asociaciones tuvo rango constitucional. Se prohibió la militancia política de los dirigentes sindicales, artículo que fue abolido con las reformas de 1989; se declaró la incompatibilidad de "los cargos directivos de las organizaciones gremiales con los cargos directivos superiores, nacionales y regionales, de los partidos políticos"; se prohibió a los dirigentes gremiales intervenir en "actividades político partidistas" y a los dirigentes de los partidos intervenir "en el funcionamiento de las organizaciones gremiales y demás cuerpos intermedios", siguiendo así la diferenciación entre el "poder político" y el "poder social”. Hasta 2005 el Senado tuvo representación corporativa a través de los senadores designados, y un Consejo de Seguridad Nacional estuvo integrado, hasta esa fecha, por los comandantes en jefe de cada rama de las fuerzas armadas. Se reconoce, pues, en estas disposiciones el ideario socialcristiano que venía proponiéndose desde las décadas de 1920 y 1930 por diversos grupos e intelectuales católicos.

\section{REFLEXIONES FINALES}

Este recorrido histórico siguiendo las propuestas políticas de los socialcristianos a lo largo del siglo XX, nos permite ilustrar la reflexión sobre las relaciones entre Iglesia y modernidad. En este artículo hemos podido apreciar una tensión, constante en el tiempo, entre dos formas de abordar la política en el contexto de la república liberal, por parte de los católicos. Si bien unos aceptan los paradigmas de la modernidad y buscan hacer política católica sin ponerlos en entredicho, los otros rechazan dichos paradigmas y se proponen crear una fórmula política propia que rompa con las alternativas de organización que ofrece el paradigma moderno, sean estas liberales o marxistas.

A fines del siglo XIX esta disyuntiva enfrentó a católicos liberales con ultramontanos al interior del Partido Conservador. Para los católicos liberales el problema fundamental de la política chilena era el fuerte autoritarismo presidencial que ahogaba la autonomía y la libertad personal, por lo que se propusieron luchar por liberalizar las relaciones políticas, combatiendo, en primer lugar, la intervención electoral del Ejecutivo. Los ultramontanos, en cambio, enfocaron el problema político chileno como uno entre clericalismo-anticlericalismo, fe y ateísmo, cristianismo y liberalismo, en último término entre catolicismo y modernidad. La jerarquía eclesiástica apoyó a los ultramontanos, motivo por el cual su postura se impuso en el Partido Conservador, lo que significó una apuesta por crear organizaciones sociales sectoriales paralelas al partido pero dependientes de la jerarquía.

Sin embargo, la capacidad del Partido Conservador de influir decisivamente en la política chilena después de la guerra civil de 1891, y de contar con una alta proporción del electorado, cambió los énfasis anteriores, de modo que la apuesta política católica, del laicado y de la jerarquía, se jugó por fortalecer las potencialidades del partido en el régimen parlamentario liberal. Por eso, el movimiento socialcristiano surgido en los años 20 se confrontó duramente con el Partido Conservador. Por lo tanto, en las primeras décadas del siglo XX, la disyuntiva católica de cómo afrontar la modernidad política, opuso a los Conservadores con los Socialcristianos. 
Si bien estos últimos tuvieron patrocinio clerical, la jerarquía eclesiástica finalmente apoyó la postura de convivencia dentro del orden político liberal que caracterizó a los Conservadores, y esta fue la que se impuso. La incorporación al Partido Conservador de una fracción decisiva de los jóvenes socialcristianos, sumado a los acontecimientos de la postguerra europea, y la transformación doctrinaria de los falangistas, dejó a los socialcristianos en la marginalidad política.

Solo en la década de 1970, bajo la dictadura militar, los socialcristianos lograron revertir su marginación. Desde la Comisión Constituyente convocada por el régimen para crear una nueva Constitución Política lograron imponer su ideario político en lo que serían las bases de la nueva institucionalidad.

De modo que podemos afirmar que para entender la postura política de los socialcristianos tenemos en primer lugar que situarlos en aquella vertiente del catolicismo que rechaza los paradigmas políticos de la modernidad. En segundo lugar, tenemos que constatar que para crear una alternativa de organización política desde paradigmas que tengan una impronta religiosa solo pueden recurrir a la única experiencia histórica de donde pueden sacar inspiración, a saber, del orden corporativo medieval. Es decir, el socialcristianismo, como expresión del anhelo de crear un modo diferente de organizar la sociedad y gobernarla según paradigmas religiosos antitéticos respecto a la modernidad, no puede escapar a las posturas corporativistas, como lo hemos podido apreciar.

Pareciera haber hoy en día un cierto intento de revitalización del corporativismo bajo apariencias progresistas, como las tuvo por lo demás en las décadas de 1920 y 30, pretensión que caracterizó también a los diversos fascismos de entre guerras. La tentación corporativista proviene del viejo y permanente anhelo de fundar una sociedad más justa con valores cristianos, y del deseo de hoy de dar representación política y capacidad de decisión a los intereses sectoriales, llamados actualmente sujetos sociales. Pero estamos ante un espejismo. Por de pronto, ¿cómo crear un orden económico corporativo cuando la economía se ha vuelto enteramente trasnacional y globalizada? Otra falacia envuelta en la tentación corporativista socialcristiana, es la presunción de que de la conjunción de los múltiples y contradictorios intereses sectoriales puede salir una política pública común, cuestión que se ha estado intentando sin éxito en las múltiples "mesas" convocadas para resolver problemas complejos, como lo fue por ejemplo en educación. Sin embargo, el principal error radica en pretender que se pueden abandonar los paradigmas de la modernidad política y mantener al mismo tiempo las libertades públicas y los derechos fundamentales. La experiencia histórica ha demostrado lo contrario: los ensayos de organización política corporativista han ido siempre de la mano de regímenes dictatoriales.

\section{RESUMEN}

En este artículo se argumenta que la preocupación por la cuestión social a comienzos del siglo XX, no fue privativa de los católicos, sino que atravesó a toda la clase política, y que, por lo tanto, lo específico del socialcristianismo como propuesta política, no es la sensibilidad social sino la opción por el corporativismo. Se sostiene que el corporativismo socialcristiano, se puede 
remontar tan atrás como el ultramontanismo conservador; que se fortalece con las encíclicas papales Rerum Novarum y Quadragessimo Anno; que su presencia se puede seguir en intelectuales y políticos católicos desde los años 30 hasta incluso los años 60; y que se puede apreciar su impronta en las "Bases de la Institucionalidad" capítulo inicial que enmarca a la Constitución de 1980. Por último, se propone que este recorrido histórico puede ser útil para reflexionar sobre la relación Iglesia y política.

Palabras clave: cuestión social, catolicismo, socialcristianismo, conservadores/liberales, corporativismo.

\begin{abstract}
In this article the author argues that concern about the social question at the beginning of the $20^{\text {th }}$ century was not exclusively a concern for Catholics, but spread throughout the entire political class. Therefore, the author further asserts that the specific thing about Social Christianity as a political proposal isn't its social sensitivity but, rather, its option for corporativism. Social Christian corporativism, it is proposed, can trace its origins as far back as conservative ultramontanism, which was backed by the papal encyclicals Rerum Novarum and Quadragessimo Anno. Its presence continued to be perceived in Catholic intellectuals and politicians from the 1930s through to the 1960s. Its impact can be appreciated in the first chapter that frames the 1980 (Chilean) Constitution, Bases de la Institucionalidad ("Foundations of Institutionality"). Finally, the author proposes that this historical review could be useful for reflections on the relationship between Church and politics.
\end{abstract}

Key words: Social question, Catholicism, Social Christianity, Conservatives/Liberals, Coroporativism. 
